\title{
Proposta de Plano de Aula sobre Paleontologia Molecular para inserção em disciplina de Paleontologia de cursos de graduação em Ciências Biológicas
}

\author{
Everton Fernando Alves ${ }^{1}$ (D) \& Márcio Fraiberg Machado $^{2}$ (D)
}

(1) Universidade de Santo Amaro, Departamento de Ciências Biológicas, Rua Isabel Schmidt 349, Santo Amaro 04743-030, São Paulo, Brasil. E-mail: efalves.mga@gmail.com

(2) Faculdade Adventista Paranaense, Departamento de Educação, PR-317 (Maringá - Campo Mourão) Km 119 Gleba, Rua Paiçandu, Lote 80 - Zona Rural, Ivatuba 87130-000, Paraná, Brasil. E-mail: profmarciofraiberg@gmail.com

Alves E.F. \& Machado M.F. (2021) Proposta de Plano de Aula sobre Paleontologia Molecular para inserção em disciplina de Paleontologia de cursos de graduação em Ciências Biológicas. Pesquisa $e$ Ensino em Ciências Exatas e da Natureza, 5: e1695.

http://dx.doi.org/10.29215/pecen.v5i0.1695

Editor acadêmico: Silvio F. B. Lima. Recebido: 22 janeiro 2021. Aceito: 09 abril 2021. Publicado: 27 abril 2021.

Resumo: A Paleontologia Molecular não tem sido contemplada nas ementas da disciplina de Paleontologia de cursos de graduação em Ciências Biológicas. No entanto, se inserida no Plano de Ensino da disciplina, a Paleontologia Molecular poderia aproximar os futuros biólogos da Paleobiologia, um campo de pesquisa praticamente inexplorado no Brasil. Logo, considera-se que a Paleontologia Molecular é relevante para compor Planos de Aula que considerem campos de pesquisa emergentes a serem explorados pelos futuros biólogos. Assim, o objetivo deste trabalho foi elaborar um Plano de Aula com conteúdos introdutórios da Paleontologia Molecular e propô-lo como modelo a ser inserido na disciplina de Paleontologia de cursos de graduação em Ciências Biológicas. A proposta final do Plano de Aula trouxe uma síntese já prevista do conhecimento paleomolecular, que poderá agilizar a ação educativa e minimizar as dificuldades que surgem durante a pesquisa e a escolha do material por parte do docente. Ademais, o instrumento é aplicável em apenas duas horas-aula. Acredita-se que, da forma como o produto educacional foi pensado, poderá enriquecer as práticas pedagógicas docentes, ampliando a bagagem de conteúdos e instrumentais didático-pedagógicos do professor e promovendo a formação de uma nova geração de profissionais mais capacitados para lidar com questões científicas emergentes.

Palavras chave: Ensino de Paleontologia, biomateriais não mineralizados, biomoléculas endógenas, instrumentos didático-pedagógicos.

Lesson Plan Proposal on Molecular Paleontology for insertion in the discipline of Paleontology of undergraduate courses in Biological Sciences

Abstract: Molecular Paleontology has not been included in the syllabus of the discipline of Paleontology in undergraduate courses in Biological Sciences. However, if inserted in the discipline's Teaching Plan, Molecular Paleontology could bring future biologists closer to Paleobiology, a field of research that is practically unexplored in Brazil. Therefore, it is considered that Molecular Paleontology is relevant for composing Lesson Plans that consider emerging research fields to be explored by future biologists. Thus, the objective of this work was to elaborate a Lesson Plan, with introductory contents of Molecular Paleontology, and to propose it as a model to be inserted in the discipline of Paleontology of undergraduate courses in Biological Sciences. The final proposal of the Lesson Plan brought an already anticipated synthesis of paleomolecular knowledge, which can streamline educational action and minimize the difficulties that arise during the research and the choice of material by the teacher. In addition, the instrument is applicable in just two class hours. It is believed that, in the way the educational product was thought, it could enrich the teaching pedagogical practices, expanding the 
baggage of the teacher's didactic-pedagogical contents and instrumentals and promoting the formation of a new generation of professionals more qualified to deal with scientific issues emerging.

Key words: Teaching Paleontology, non-mineralized biomaterials, endogenous biomolecules, didacticpedagogical instruments.

\section{Introdução}

A Paleontologia Molecular é um campo de pesquisa interdisciplinar que se dedica a recuperar e caracterizar os achados de biomateriais não mineralizados presentes em fósseis de seres extintos das mais diversas idades com o auxílio de distintas técnicas moleculares avançadas e complementares de detecção ultraestruturais (Schweitzer 2003, 2004).

A expressão biomateriais não mineralizados é definida como um conjunto de materiais biológicos que incluem os tecidos moles, células, moléculas orgânicas ou seus produtos de degradação, a nível de grupos funcionais úteis para rastreamento da molécula original, que não são tecidos originalmente biomineralizados (e.g., ossos), e que de alguma forma não foram substituídos por minerais durante a fossildiagênese (Schweitzer 2003, 2004; Alves \& Machado 2020).

Desde a década de 1950 (Abelson 1956; Whitear 1956), dezenas de pesquisas já reivindicaram preservação de diversos tipos de biomateriais não mineralizados, tais como estruturas do tecido epitelial e conjuntivo, vasos sanguíneos, hemácias, osteócitos, remanescentes bioquímicos como proteínas, lipídios, pigmentos de melanina, compostos intracelulares quimicamente consistentes com o DNA e dados de sequências peptídicas, incluso os de proteínas histonas, entre outros (Schweitzer 2011; Thomas \& Taylor 2019; Alves \& Machado 2020; Bailleul et al. 2020; Gomes et al. 2020a,b; van der Reest \& Currie 2020).

O estabelecimento oficial da Paleontologia Molecular como uma área de pesquisa promissora é bem recente, tendo sido popularizada a partir do ano de 2005 (Alves 2020). As investigações paleomoleculares são inovadoras e têm produzido grandes volumes de dados (Thomas \& Taylor 2019), contribuindo, especialmente, para a compreensão da biologia e dos processos evolutivos de organismos extintos.

Por outro lado, no Brasil, ainda hoje, a Paleontologia Molecular é um campo praticamente inexplorado. A ideia de inserção de uma aula específica sobre esse tema durante a disciplina de Paleontologia para cursos de graduação em Ciências Biológicas, em ambos os graus bacharelado e licenciatura, justifica-se, pois cada vez mais grupos de pesquisas internacionais vêm se estruturando para investigações moleculares aplicadas à Paleontologia. Enquanto isto, verifica-se que, em solo nacional, poucas pesquisas já foram publicadas a respeito do tema.

É de responsabilidade dos professores universitários e gestores educacionais proporcionarem um currículo atualizado que responda as necessidades dos futuros profissionais da Biologia (Carrijo \& Candeiro 2010). No entanto, pesquisas têm mostrado o problema da falta de atualização de professores responsáveis pelo ensino da disciplina de Paleontologia (Godov et al. 2017).

É necessário que tais professores acompanhem as mudanças do conhecimento científico, pois elas terão grande impacto sobre a sua prática (Godov et al. 2017). No Brasil, por exemplo, a abordagem de temas atuais da Paleontologia no ensino básico fica a cargo dos professores, o que pode resultar num tratamento insuficiente em sala de aula, uma vez que a própria formação dos professores nesta disciplina parece ser precária (Carrijo \& Candeiro 2010; Zucon et al. 2010; Compagnon et al. 2016; Sousa et al. 2016; Silva et al. 2019).

No ensino superior também parece existir um despreparo dos professores no que diz respeito ao ensino da Paleontologia em cursos de graduação em Ciências Biológicas, uma vez que os dados mostram que estudantes universitários de Biologia desconhecem conteúdos gerais dessa disciplina mesmo após a terem cursado (Alves et al. 2019; Araújo 2020). Dessa forma, a Paleontologia, em geral, é tratada de maneira fragmentada e descontextualizada, não sendo explorado todo o seu potencial pedagógico. 
Deste modo, acredita-se que a inserção de conteúdos paleomoleculares no currículo formal dos futuros biólogos incentivará a formação de novos profissionais da Paleobiologia a fim de atuarem nessa área de pesquisa promissora, impulsionando rapidamente esse campo de pesquisa e expandindo nosso entendimento sobre a evolução dos organismos extintos e os processos envolvidos na fossildiagênese. Até onde se sabe, não existe no Brasil nenhuma proposta de desenvolvimento de um Plano de Aula prático e criterioso para o ensino da Paleontologia Molecular em nível de graduação.

Diante disso, objetivou-se neste trabalho elaborar um Plano de Aula, com conteúdos introdutórios da Paleontologia Molecular, e propô-lo como modelo a ser inserido na disciplina de Paleontologia de cursos de graduação em Ciências Biológicas - graus bacharelado e licenciatura.

\section{A deficiência no ensino da Paleontologia Molecular nos cursos de graduação em Ciências Biológicas}

Diversas pesquisas vêm sendo feitas ao longo do tempo mostrando que são variadas as razões da Paleontologia ser pouco trabalhada na educação básica, a saber: inexistência ou abordagem reduzida de conteúdos da Paleontologia e das Geociências nos Currículos Mínimos das Secretarias de Estado de Educação do País (Teixeira 2016; Duarte et al. 2019), carência de tais temas nos livros didáticos da educação básica (Compagnon et al. 2016), pouca ou nenhuma cobrança desses assuntos nos processos seletivos como concursos, vestibulares e uma má compreensão dos temas em ambientes educacionais devido à crendices (Teixeira 2016).

De igual forma, é precário o ensino da Paleontologia para estudantes universitários e para professores já formados em Ciências Biológicas. Pesquisas têm identificado conceituações e perspectivas equivocadas sobre o conhecimento deles a respeito da Paleontologia e das Geociências, evidenciando uma formação de professores deficiente ou pouco atualizada a respeito de tais assuntos (Sousa et al. 2016; Duarte et al. 2019).

Outro ponto relacionado ao baixo nível de conhecimento em Paleontologia e Geologia de professores do ensino básico é a carga horária reduzida dessas disciplinas durante os cursos de licenciatura, formando, desta maneira, uma geração de professores despreparados para trabalharem de maneira eficaz os temas de Paleontologia e Geociências em sala de aula (Compagnon et al. 2016; Duarte et al. 2019). Isso prejudica seriamente a propagação do ensinoaprendizagem das geociências (Duarte et al. 2018; Sousa et al. 2016).

Por outro lado, o aumento de horas por si só na carga horária da disciplina de Paleontologia não resolveria o problema de aplicação e contextualização de conteúdos (Carrijo \& Candeiro 2010). Torna-se necessário analisar e adequar o currículo da disciplina à época em que vivemos para que o mesmo contemple também as inovações e os clássicos, e se incorpore tais conteúdos às atividades formativas dos futuros profissionais da Biologia.

Diante disso, fica mais fácil compreender as dificuldades que o processo de ensino e aprendizagem da Paleontologia enfrenta na disseminação de conceitos tanto básicos quanto específicos, como no caso da Paleontologia Molecular. Dra. Mary Schweitzer (Universidade Estadual da Carolina do Norte), paleontóloga considerada a responsável pelo estabelecimento oficial do campo da Paleontologia Molecular a nível mundial (Bailleul et al. 2019), diz que,

\footnotetext{
Meu palpite é que o Brasil não é diferente de outros lugares, pois, para começar, muito pouca atenção é dada ao ensino das ciências paleontológicas. A Paleontologia Molecular, sendo apenas um pequeno subconjunto do campo maior, é muito improvável de ser ensinado de forma mais ampla em qualquer lugar (Comunicação pessoal - 18 de janeiro de 2021).
}

Os alunos que cursam a disciplina de Paleontologia recebem pouco ou nenhum treinamento em Paleontologia Molecular durante seus anos de graduação (Schweitzer 2003). No entanto, ensinar temas relacionados a essa área durante a formação de jovens profissionais da Biologia poderia fortalecer a objetividade da disciplina de Paleontologia, bem como fornecer um 
meio independente de testar hipóteses filogenéticas (Schweitzer 2003). A busca desse conhecimento é valiosa e auxiliará a compreensão dos processos evolutivos, da Biologia e da Ecologia de organismos extintos e modernos, bem como dos processos de fossilização, principalmente no nível molecular.

Logo, para mudar a realidade de um ensino deficitário ou possivelmente inexistente da Paleontologia Molecular durante a graduação, é necessário que os estudantes de Biologia sejam ensinados, durante a disciplina de graduação em Paleontologia, a respeito dos registros genômicos e geológicos, a fim de integrarem em suas bagagens os dois conjuntos de informações que fornecem respostas para questões relacionadas à história da vida na Terra, especialmente em um clima atual de pós-genômica (Schweitzer 2003).

Outro problema é que a Paleontologia, em geral, é pouco abordada nos livros didáticos e quando ocorre é sob uma visão bastante superficial dos conteúdos, tratando apenas dos grandes répteis e ocultando, muitas vezes, outras subdisciplinas como, por exemplo, a Micropaleontologia, Icnologia e Paleobotânica (Lima et al. 2015). Para os alunos de graduação em Ciências Biológicas, a única imagem ensinada sobre Paleontologia é a de restos de ossos de dinossauros apresentada pela mídia.

Até onde se sabe, não existem livros didáticos oficiais e específicos sobre Paleontologia Molecular voltados a estudantes de graduação em Ciências Biológicas. Existem alguns materiais específicos para a pós-graduação ou para o campo da Arqueologia Molecular (Degusta 2002; DeSalle \& Egan 2006; Gupta 2014).

Uma opção a ser utilizada na preparação das aulas para cursos de graduação em Ciências Biológicas é um livro recém-publicado pela Dra. Mary Schweitzer e colaboradores, intitulado Dinosaurs: How We Know What We Know, que se destina a alunos de graduação a fim de apresentá-los a todas as subdisciplinas da Paleontologia dos dinossauros, incluindo a Tafonomia e informações sobre biomateriais originais (Schweitzer et al. 2020). Com essa introdução, os professores e alunos certamente podem ter uma ideia melhor de como focar seus estudos.

Para aqueles professores que desejam ensinar, ainda que sejam apenas conceitos básicos de Paleontologia Molecular, a dica principal é usar basicamente trabalhos da literatura primária. Quanto ao quê ensinar, a Dra. Mary Schweitzer dá algumas dicas:

\footnotetext{
No nível de graduação, é muito mais importante ensinar o aluno como fazer perguntas científicas e avaliar dados. A primeira coisa que perguntei quando vi aqueles vasos sanguíneos e osteócitos pela primeira vez foi: 'o que mais eles podem ser, porque com certeza não podem ser o que parecem?' Eles são fungos? Não, eu descartei isso quimicamente e microscopicamente. Eles são algum tipo de biofilme bacteriano? Não, eu também descartei isso. Só eliminando outras possibilidades podemos seguir em frente. No final, talvez sejam o que parecem! (Comunicação pessoal - 02 de janeiro de 2021).
}

A disciplina de Paleontologia, por sua natureza multidisciplinar, também pode apresentar aos alunos distintos aspectos de diversas ciências básicas (Kellner 2015). Uma delas diz respeito à Tafonomia que é um campo de estudo fundamental para a compreensão da Paleontologia Molecular. A Tafonomia é o estudo dos processos que direcionam todas as modificações em um organismo, desde sua morte até a fossilização (Martindale \& Weiss 2020).

A respeito disso, e quanto ao conteúdo prévio que os alunos devem ter antes de aprender Paleontologia Molecular, a Dra. Mary Schweitzer também explica que,

Paleontologia Molecular é apenas a Biologia Molecular de coisas antigas, com algumas modificações. Se os alunos tiverem uma boa base em Química, Bioquímica, Biologia Molecular, Geoquímica, Histologia, entre outras disciplinas básicas, eles devem ser capazes de assimilar facilmente o conteúdo. Uma diferença importante, porém, é a compreensão dos processos de Tafonomia, porque são eles que afetam a recuperação molecular. A forma como as moléculas são modificadas no processo de degradação requer algumas mudanças nos métodos usados para recuperar e analisar esses materiais. Afinal, você não esperaria que não houvesse diferenças entre os vasos sanguíneos dos 


\begin{abstract}
animais modernos e os que têm 65 milhões de anos! Eles devem ser modificados para sobreviver, certo? Então, entender isso também é importante. Eu acho que no nível de graduação, discutir essas modificações e introduzir a ideia de que elas podem estender a vida molecular em ordens de magnitude, e as implicações disso, provavelmente poderiam ser realizadas em uma única aula, e isso é provavelmente tudo que um aluno de graduação precisaria receber (Comunicação pessoal - 02 de janeiro de 2021).
\end{abstract}

Por isso, é que os processos tafonômicos têm recebido muita atenção dos paleontólogos. Por outro lado, a Tafonomia pode se tornar um conceito difícil para os estudantes (Martindale \& Weiss 2020), mais especificamente, as escalas de tempo e os processos biogeoquímicos envolvidos na fossilização são, frequentemente, desafiadores para os alunos (Ault 1984; Kortz \& Murray 2009). Mas, embora real essa situação, na proposta apresentada, pode ser pulverizada nos conteúdos inerentes e associados às temáticas que dão suporte ao ensino de forma dinâmica $\mathrm{e}$ sequenciada. A fossilização é complexa e envolve fatores como biologia do organismo, micro ambiente local, química do oceano global e processos diagenéticos (Gobbo \& Bertini 2015; Alves \& Machado 2020). À propósito, muitos alunos podem considerar esses fatores abstratos e a interação entre eles ainda mais difícil de ser assimilada e sintetizada (Martindale \& Weiss 2020).

Portanto, é fundamental que os professores da disciplina de Paleontologia de cursos de graduação em Ciências Biológicas incorporem nos planos de aula conteúdos atuais, como o caso da Tafonomia Molecular e a preservação excepcional de biomateriais não mineralizados em fósseis, que derivam das mudanças de foco das pesquisas paleontológicas e se utilizam de metodologias cada vez mais sofisticadas (Kellner 2015). Um bom exemplo é o uso de novas técnicas analíticas como a tomografia computadorizada que possibilita uma reconstrução detalhada da preservação de órgãos e tecidos moles internos nos organismos fósseis. Essa é uma boa oportunidade para se apresentar também diversos conceitos relacionados à Física, sem contar com as diversas possibilidades de tecnologias que podem ser empregadas para a busca de biomoléculas endógenas, esta sim a grande revolução das últimas duas décadas.

O grande desafio da Paleontologia para a década em que vivemos estará na educação de novos profissionais da Biologia (Worheide et al. 2016). Isso porque uma parcela deles, por meio de aulas de Ciências e Biologia, na Educação Básica, será responsável pela educação de uma nova geração de pesquisadores, enquanto que a outra parcela se aventurará diretamente nas pesquisas, inclusive da Paleontologia, uma vez que o curso de Biologia é o caminho tradicional para entrada nas pesquisas paleontológicas.

Até pouco tempo atrás, a biologia orgânica e molecular e a genômica ainda desempenhavam um papel secundário na formação do futuro biólogo. Hoje, é necessário que currículos de graduação combinem, explicitamente, esses dois campos aparentemente díspares para preparar novas gerações de acadêmicos interdisciplinares bem formados para os novos desafios metodológicos e intelectuais que enfrentam na exploração e compreensão da história da vida em uma perspectiva de tempo profundo (Worheide et al. 2016).

Assim, acredita-se que, a partir do momento em que jovens acadêmicos estiverem bem formados interdisciplinarmente, podendo dominar tanto o registro fóssil quanto o laboratório molecular com uma perspectiva de tempo profundo, a Paleontologia Molecular se tornará um dos principais pilares de pesquisas paleontológicas inovadoras do futuro.

\title{
Desenvolvimento do Plano de Aula
}

A metodologia aplicada na construção do Plano de Aula, desenvolvido para a disciplina de Paleontologia de cursos de graduação em Ciências Biológicas, foi escolhida e adaptada após anos de leitura de diversos papers em distintas bases de dados da literatura científica, além de experiência dos autores com o ensino extensivo da Paleontologia Molecular. A seleção dos artigos se deu de forma arbitrária a fim de abarcar um maior quantitativo de textos que, qualitativamente, teriam a contribuir com as propostas da Paleontologia Molecular.

O Plano de Aula pode ser definido como um instrumento pedagógico que prevê os conteúdos e atividades de uma ou de várias aulas que compõem uma determinada disciplina 
(Góes et al. 2015). Ainda pode ser entendido como a descrição sistemática da sequência de atividades de tudo o que vai ser desenvolvido pelo professor na sala de aula em um ou mais dias letivos, tendo em vista o que se espera alcançar como objetivos junto aos alunos (Libâneo 1993; Góes et al. 2015). Alguns autores entendem o Plano de Aula como um detalhamento do plano de ensino. Gil (2012: 39) explica que "o que difere o plano de ensino do Plano de Aula é a especificidade com conteúdos pormenorizados e objetivos mais operacionais”.

Aliás, "uma boa aula é aquela que foi pensada e preparada" (Góes et al. 2015: 5). Ainda segundo Góes e colaboradores, pensar e planejar o que acontecerá em uma aula "é fundamental para criar um ambiente adequado para a construção do conhecimento pelos alunos, além de trazer maior segurança e domínio ao professor daquilo que será desenvolvido.” (Góes et al. 2015: 4).

O Plano de Aula, como um instrumento pedagógico de ensino, é aquele que possui objetivos próprios com características temáticas, composicionais e estilos demarcados (Hilá 2008). As seções que compõem o Plano de Aula representam as partes principais e essenciais de norteamento de uma aula. Para construção das seções, eu tenho que responder as seguintes perguntas:

\footnotetext{
O que eu pretendo que meus alunos sejam capazes de fazer depois do que eu ensinei e que não podiam fazer antes? Em que nível eles são capazes de fazer? Como faço para promover atividades que irão ajudá-los a alcançar os resultados pretendidos da aprendizagem? Como posso avaliá-los para ver se eles alcançaram tais resultados? (Biggs \& Tang 2011 cf. Mendonça 2015: 2)
}

Pensando nessas questões relativas à sua estrutura composicional, o Plano de Aula desenvolvido neste trabalho (Anexo I - Plano de Aula) adotou as seguintes seções: 1) Ementa; 2) Objetivos (geral e específicos); 3) Conteúdo programático; 4) Recursos didáticos; 5) Procedimentos de avaliação; e 6) Bibliografia.

\section{Ementa}

A sequência de aula descrita no Plano de Aula foi pensada para o nível de graduação e pressupõe a capacidade do aluno para avaliação crítica da literatura científica. Isso porque é muito mais importante durante o aprendizado da Paleontologia, no nível de graduação, ensinar os alunos como fazer perguntas científicas e avaliar dados.

Conforme visto anteriormente, é essencial que o estudante universitário tenha familiaridade com o conhecimento básico prévio de Química e Biologia Molecular. Isso porque a Paleontologia Molecular pode ser compreendida como a identificação de informações químicas e moleculares a partir de biomateriais preservados em tempo profundo.

Uma vez que a disciplina de Paleontologia geralmente é ofertada no penúltimo ou último ano de cursos de graduação em Ciências Biológicas - graus bacharelado e licenciatura (Unicesumar 2017a,b), subentende-se que os estudantes já tenham tais conhecimentos prévios por terem sido aprovados em disciplinas básicas, e, portanto, eles devem ser capazes de assimilar o conteúdo do Plano de Aula.

Diante disso, a proposta do desenvolvimento de um Plano de Aula considerado ideal a respeito de conteúdos introdutórios da Paleontologia Molecular levou em consideração para a ementa os seguintes tópicos:

- Breve história do campo de pesquisa, conceitos e terminologias básicas da área;

- Classes de biomoléculas de diferentes idades geológicas quanto ao seu potencial de preservação;

- Biomarcadores e métodos de recuperação de biomoléculas de fósseis;

- Tipos de informações que as biomoléculas produzem sobre a biologia, fisiologia e relações filogenéticas de organismos extintos;

- Noção geral dos recursos básicos de um laboratório paleomolecular; 
- Os diferentes grupos de técnicas analíticas empregados para recuperar e interpretar biomoléculas originais em fósseis e critérios para determinar sua endogeneidade;

- Mecanismos diagenéticos de preservação e modificação molecular ao longo do tempo, e aspectos da geoquímica no que se refere à retenção/preservação molecular.

- Perspectivas futuras e as implicações da Paleontologia Molecular para outras disciplinas.

\section{Objetivos}

Os objetivos do Plano de Aula a serem alcançados foram pensados a fim de contemplar tanto o objetivo geral da aula quanto os objetivos específicos, a saber:

\subsection{Objetivo geral}

- Ensinar a importância das pesquisas paleomoleculares para a compreensão da evolução de organismos extintos.

\subsection{Objetivos específicos}

- Avaliar criticamente a literatura pertinente e desenvolver habilidades de leitura crítica;

- Discutir os processos de diagênese e Tafonomia em nível molecular, incluindo vários modos de preservação e modificações químicas em moléculas preservadas no registro fóssil;

- Discorrer sobre os principais grupos de técnicas de última geração para identificação de biomoléculas endógenas em fósseis;

- Levar o aluno a compreensão do potencial de preservação molecular e à adquirir habilidade de diferenciar a preservação de várias classes de biomoléculas.

\section{Conteúdo programático}

Nesta etapa, procurou-se elencar doze temas que, em conjunto, possibilitasse ao estudante, no nível de graduação, a síntese da ideia a respeito das modificações sofridas pelas biomoléculas endógenas e a relação que isso tem com a extensão da vida molecular em ordens de magnitude.

Acredita-se que esses doze tópicos podem ser ensinados em apenas duas horas-aula (ou seja, seis tópicos para cada hora-aula), sendo provavelmente o conjunto total de conhecimento que um aluno de graduação em Ciências Biológicas precisará saber sobre aspectos introdutórios da Paleontologia Molecular. A seguir, estão os tópicos que irão compor o conteúdo programático do Plano de Aula:

\section{$1^{\text {a }}$ hora-aula:}

- Breve histórico da Paleontologia Molecular;

- Definições, ramos da Paleontologia Molecular e campos de pesquisa;

- Objeto de estudo, biomarcadores e classes de biomoléculas originais encontradas em fósseis;

- Diagênese das rochas, Tafonomia, preservação excepcional e tipos de biomateriais em relação à diagênese das rochas de depósitos sedimentares Konservat-Lagerstätten;

- Principais achados de biomoléculas distribuídos ao longo da coluna geológica;

- Introdução ao laboratório de Paleontologia Molecular e métodos analíticos de deteç̧ão de biomoléculas; 


\section{$2^{\text {a hora-aula: }}$}

- Proteínas e DNA antigos e métodos de detecção;

- Aplicações práticas da Paleontologia Molecular: estudo de casos brasileiros;

- A importância da pesquisa teórica brasileira relativa à frequência de ocorrência de achados de biomateriais não mineralizados no mundo;

- Sobrevivência esperada de biomoléculas a diferentes temperaturas;

- Principais mecanismos diagenéticos de preservação de biomoléculas originais e as mais relevantes controvérsias relacionadas;

- Perspectivas futuras da Paleontologia Molecular, discussão e avaliação;

Um ponto importante na construção do conteúdo programático foi a inserção do campo "Leituras", em uma coluna lateral. Neste campo, ao lado de cada tópico, foram elencados os artigos científicos da literatura primária correspondentes a cada sugestão de tema da aula, os quais o professor conseguirá consultar por conta própria e avaliar a pertinência do assunto previsto e, se preferir, inserir novos subtópicos para uma abordagem ainda mais específica em sala de aula.

Dessa forma, este Plano de Aula pode ser visto como um instrumento flexível, passível de ser adaptado para diferentes realidades pedagógicas no processo de ensino-aprendizagem da Paleontologia Molecular.

Outro diferencial do Plano de Aula diz respeito à contextualização dos temas. Pesquisas têm mostrado que a Paleontologia, em geral, tem sido ensinada de forma superficial, descontextualizada e desconectada da realidade do estudante, desde o ensino básico ao superior (Carrijo \& Candeiro 2010; Oliva 2018). Acredita-se que o motivo se deve ao fato de no momento de se montar um Plano de Aula, acabe sendo incorporados ao seu conteúdo programático temas desatualizados, questões artificiais e exemplos estrangeiros, o que gera um aprendizado pouco significativo aos estudantes (Cotts \& Prestes 2013).

Pensando nisso, considerou-se neste trabalho que, voltar-se para o cotidiano dos alunos e, mais especificamente, para a espacialidade e temporalidade do contexto real dos futuros biólogos, poderia facilitar o processo de assimilação de conteúdo e despertar neles um aprendizado mais significativo (Campos 2015).

Assim sendo, optou-se por inserir no Plano de Aula, por exemplo, conteúdos contextualizados que dizem respeito às aplicações práticas da Paleontologia Molecular, publicadas por grupos de pesquisa brasileiros, e tópicos sobre os levantamentos da frequência de ocorrência de achados de biomateriais não mineralizados em diversas regiões do planeta, também realizados em nosso País, e a importância de ambas as investigações tanto para o desenvolvimento de futuras pesquisas paleomoleculares mais especializadas quanto para o progresso da ciência nacional.

Acreditamos que estratégias como essa podem despertar no estudante um senso maior de pertencimento e promover um novo olhar para o seu próprio potencial de contribuição para novos ramos da ciência, aventurando-se em campos de pesquisa praticamente inexplorados como no caso da Paleontologia Molecular.

Por último, mas não menos importante, é o item discussão inserido ao final do conteúdo programático. Por que ele seria importante para o aprendizado da Paleontologia Molecular? Conforme visto anteriormente, a melhor maneira de aprender abordagens paleomoleculares é formulando uma pergunta de pesquisa e descobrindo o que você precisa para respondê-la e como você pode fazer para respondê-la. É nesse momento que o estudante poderá exercitar essa habilidade de formular perguntas ainda não pensadas para um conteúdo científico emergente. É nesse momento também que o professor deve observar as perguntas que estão sendo feitas, e direcionar quais perguntas os alunos deveriam fazer ao invés de outras. 


\section{Recursos didáticos}

As aulas não exigem recursos didáticos incomuns para que o ensino-aprendizagem do conteúdo seja efetivo, bastando possuir em sala de aula equipamento para apresentação de slides em PowerPoint, tal como computador e projetor multimídia, além de quadro negro e giz (ou quadro branco e pincel).

\section{Procedimentos de avaliação}

Propõe-se que a participação em sala de aula e a leitura de materiais sugeridos antes da discussão em classe poderiam representar $20 \%$ da nota final. Recomenda-se que ao final da aula seja empregada uma atividade avaliativa, que objetiva identificar e sistematizar se, de fato, as aprendizagens foram sedimentadas e quais as possíveis falhas relacionadas ao próprio método empregado no Plano de Aula.

Para tanto, elaborou-se como modelo aplicável um questionário semi-estruturado (Anexo II - Questionário) contendo 15 questões (14 objetivas e 1 discursiva), baseadas no conteúdo programático, as quais o professor poderá selecionar a quantidade que achar viável para a avaliação em sala de aula a fim de compor o restante da nota (no caso, $80 \%$ da nota final).

\section{Bibliografia}

Localizada ao final do Plano de Aula, fora elencada uma lista de materiais consultados (livros e artigos) sob a qual fora desenvolvida a proposta da aula. Essa lista foi dividida em bibliografia básica e complementar.

Quadro 1. Resumo das seções que compõem o Plano de Aula.

\begin{tabular}{|c|c|c|c|}
\hline \multirow{9}{*}{ Seções } & \multicolumn{2}{|c|}{ Dados de identificação } & $\begin{array}{l}\text { Campos onde o professor deve inserir, por exemplo, o } \\
\text { nome da disciplina, do curso e a turma que participará da } \\
\text { aula. A identificação auxilia previamente o professor no } \\
\text { conhecimento, no planejamento e decisão de etapas } \\
\text { fundamentais do Plano de Aula }\end{array}$ \\
\hline & \multicolumn{2}{|c|}{ Ementa } & $\begin{array}{l}\text { Lista de conteúdos que possibilita uma visão global do } \\
\text { programa da disciplina }\end{array}$ \\
\hline & \multicolumn{2}{|c|}{ Objetivo geral } & $\begin{array}{l}\text { Aspecto amplo relacionado ao que se espera atingir com } \\
\text { o processo de ensino-aprendizagem da Paleontologia } \\
\text { Molecular }\end{array}$ \\
\hline & \multicolumn{2}{|c|}{ Objetivos específicos } & $\begin{array}{l}\text { Norteadores para alcançar a finalidade do objetivo geral. } \\
\text { Estão relacionados a "bagagem de conhecimento" que, } \\
\text { após a aula, espera-se que seja adquirida pelos futuros } \\
\text { biólogos }\end{array}$ \\
\hline & \multicolumn{2}{|c|}{ Conteúdo programático } & $\begin{array}{l}\text { Lista de tópicos pormenorizados que compõem a aula. } \\
\text { Essa lista deve manter relação estreita com a ementa. } \\
\text { Para cada tópico do conteúdo programático, foi inserido } \\
\text { no campo lateral "Leituras" uma listagem de materiais } \\
\text { consultados }\end{array}$ \\
\hline & \multicolumn{2}{|c|}{ Recursos didáticos } & $\begin{array}{l}\text { Material utilizado como auxílio no ensino-aprendizagem } \\
\text { do conteúdo proposto para ser aplicado em sala de aula } \\
\text { pelo professor a seus alunos }\end{array}$ \\
\hline & \multicolumn{2}{|c|}{ Procedimentos de avaliação } & $\begin{array}{l}\text { Breve descrição da proposta das atividades que o professor } \\
\text { poderá utilizar para avaliar o aluno após todo o conteúdo } \\
\text { ter sido ensinado }\end{array}$ \\
\hline & \multirow{2}{*}{ Bibliografia } & Básica & $\begin{array}{l}\text { Composta por um conjunto de materiais que, de modo } \\
\text { geral, expõem todo, ou grande parte do conteúdo da } \\
\text { disciplina }\end{array}$ \\
\hline & & Complementar & $\begin{array}{l}\text { Composta por um conjunto de materiais que possibilitam } \\
\text { o aprofundamento do estudo acerca de certos aspectos ou } \\
\text { pontos do conteúdo }\end{array}$ \\
\hline
\end{tabular}




\section{Considerações finais}

Em um primeiro momento, procurou-se construir essa primeira versão do Plano de Aula para que, numa etapa futura, novas pesquisas possam introduzir esse instrumento didáticopedagógico em salas de aula de Paleontologia e verificar a sua eficácia no processo de ensinoaprendizagem.

Percebeu-se que a Paleontologia Molecular está em constante avanço e se torna até difícil acompanhar o grande volume de dados científicos que tem sido publicado nesta área a nível mundial. Portanto, de igual forma, é cada vez mais difícil para o professor universitário responsável pela disciplina de Paleontologia acompanhar as novidades científicas da área.

Esta pesquisa possui caráter de ineditismo, uma vez que não houve, até o presente momento, nenhum trabalho publicado que tentasse unificar o ensino da Paleontologia Molecular, no nível de graduação em Ciências Biológicas, por meio de um Plano de Aula facilitado e simples de ser aplicado em apenas duas horas-aula.

A proposta deste Plano de Aula, da forma como foi pensada e planejada, traz uma síntese já prevista do conhecimento paleomolecular. Por isso, acredita-se que este produto educacional contribuirá para o processo da prática pedagógica direcionada, agilizando a ação educativa e minimizando as dificuldades que surgem durante a pesquisa e a escolha do material por parte do docente.

Espera-se, além disso, que este produto educacional possa contribuir de forma democrática para o enriquecimento das práticas pedagógicas de professores de Paleontologia, no nível de graduação em Ciências Biológicas, ampliando a bagagem de conteúdos e instrumentais didático-pedagógicos e promovendo a formação de uma geração de profissionais da Biologia mais capacitados para lidar com questões científicas emergentes.

Também é necessário levar em consideração que cada região possui suas próprias especificidades, logo, o objetivo com este Plano de Aula é servir apenas de modelo, podendo o mesmo ser adaptado para diversos tipos de realidades pedagógico-educacionais existentes em nosso país.

\section{Agradecimentos}

Aos avaliadores pelas críticas construtivas ao texto.

\section{Referências}

Abelson P.H. (1956) Paleobiochemistry. Scientific American, 195(1): 83-92.

Alves E.F. (2020) 15 anos da Paleontologia molecular: breve histórico dos achados de tecidos moles não mineralizados em dinossauros não avianos. Revista de História da Ciência, 9: 241244. https://doi.org/10.11606/khronos.v0i9.172317

Alves E.F. \& Machado M.F. (2020) Perspectivas atuais sobre tecidos moles não mineralizados em fósseis de dinossauros não avianos. Terræ Didatica, 16: e020028.

https://doi.org/10.20396/td.v16i0.8659539

Alves E.F., Beier E.V., Vidotti A.P. \& Miranda Neto M.H. (2019) Autopercepção de mediadores no Museu Dinâmico Interdisciplinar acerca do nível de conhecimento em Paleontologia para a educação não formal. Anais. Jaguariaíva: XXI Paleo PR-SC.

Araújo L.A.L. (2020) Concepções equivocadas sobre evolução biológica: um estudo comparativo entre graduandos em ciências biológicas e Pós-graduandos. Investigações em Ensino de Ciências, 25(2): 332-346. https//doi.org/10.22600/1518-8795.ienci2020v25n2p332

Ault C.R. (1984) The everyday perspective and exceedingly unobvious meaning. Journal of Geological Education, 32(2): 89-91. https://doi.org/10.5408/0022-1368-32.2.89

Bailleul A.M., O'Connor J., Zhang S., Li Z., Wang Q., Lamanna M.C., Zhu X. \& Zhou Z. (2019) An Early Cretaceous enantiornithine (Aves) preserving an unlaid egg and probable medullary bone. Nature communications, 10(1): 1275. https://doi.org/10.1038/s41467-019-09259-x 
Bailleul A.M., Zheng W., Horner J.R., Hall B.K., Holliday C.M., \& Schweitzer M.H. (2020) Evidence of proteins, chromosomes and chemical markers of DNA in exceptionally preserved dino-saur cartilage. National Science Review, 7(4): 815-822. https://doi.org/10.1093/nsr/nwz206

Campos C.R.P. (2015) Aula de Campo para Alfabetização científica: práticas pedagógicas escolares. Volume 6. Vitória: Editora Ifes. 284 p.

Carrijo R. \& Candeiro C.R. (2010) O Ensino de Geologia, Paleontologia e Química no Centro Universitário do Planalto de Araxá (Uniaraxá). A importância da Geociências. Revista de Biologia e Ciências da Terra, 10(1): 62-66.

Compagnon J.M., Maciel E.S., Cidade M.P., Melo R.M., Costa E.R. \& Feltran R.B. (2016) A Paleontologia no processo de Ensino Aprendizagem dos alunos do $7^{\circ}$ Ano da sede do município de Boa Vista, Roraima. In: XI Semana Nacional de Ciência e Tecnologia no Estado de Roraima. Anais. Roraima: SNCT-RR.

Cotts L. \& Prestes S.B.S. (2013) O ensino de paleontologia na educação básica: uma abordagem lúdica. Boletim informativo da SBP, 29(67): 16.

Degusta D. (2002) Molecular Archeology and Paleontology (Methods in Molecular Biology). Totowa: Humana Press. 400 p.

DeSalle R. \& Egan M.G. (2006) Paleontology, molecular (p. 53-70). In: Meyers RA. (Ed.). Encyclopedia of Molecular Cell Biology and Molecular Medicine. $2^{\circ}$ Edition. Weinheim: Wiley-VCH. https://doi.org/10.1002/3527600906.mcb.200400057

Duarte S.G., Martins C.M.M.R., Bandeira L.G., Carramillo L.C., Gervásio C.M. \& Wanderley M.D. (2018) Experiência interdisciplinar na educação básica e na formação de professores: Artes, Biologia e Geociências. Terræ Didatica, 14(3): 245-255. https://doi.org/10.20396/td.v14i3.8652424

Duarte S.G., Santos N.M., Bandeira L.G., Martins C.M.M.R., Pereira M.G. \& Caetano L.C. (2019) Conhecimento prévio de Paleontologia e Geologia de ingressantes em cursos de Ciências Biológicas e Geologia de universidades do Rio de Janeiro. Terræ Didatica, 15: e19032. https://doi.org/10.20396/td.v15i0.8654529

Gil A.C. (2012) Metodologia do ensino superior. $4^{\circ}$ edição. São Paulo: Atlas. 128 p.

Gobbo S.R. \& Bertini R. (2015) Tecidos moles (não resistentes): como se fossilizam? Terræ Didatica, 10(1): 2-13. https://doi.org/10.20396/td.v10i1.8637374

Godov P.L., Ferreira G.S., Dassie E.C.G., Corrêa e Castro A.C.M. \& Hsiou A.S. (2017) Formação continuada no ensino de Paleontologia, pelo exemplo do projeto "Oficina de Paleontologia: os fósseis dentro da sala de aula”. Revista de Cultura e Extensão USP, 17: 11-19. https://doi.org/10.11606/issn.2316-9060.v17isupl.p11-19

Góes F.S.N., Andrade A.S., Corrêa A.K., Mello e Souza M.C.B., Clapis M.J., Gonçalves M.F.C., Silva M.A.I. \& Camargo R.A.A. (2015) Plano de aula: apoio e fundamentos para prática docente. Ribeirão Preto: Escola Enfermagem Ribeirão Preto/USP. 90 p.

Gomes W.A., Machado M.F., Bélo P. \& Alves E.F. (2020a) Paleontologia molecular do Cenozoico: reivindicações de tecidos moles não mineralizados em mamíferos encontrados em depósitos sedimentares pouco favoráveis à preservação. Paleo RJ/ES Virtual, Vitória, Espírito Santo.

Gomes W.A., Machado M.F., Bélo P. \& Alves E.F. (2020b) Biomoléculas em fósseis de mamíferos cenozoicos: reivindicações de tecidos moles não mineralizados em fósseis recuperados de diferentes contextos tafonômicos. Paleo RJ/ES Virtual, Vitória, Espírito Santo.

Gupta N.S. (2014) Biopolymers - A molecular paleontology approach (Topics in Geobiology). Volume 38. Dordrecht: Springer. 199 p.

Hilá C.V.D. (2008) O gênero artigo de opinião: diagnóstico e intervenção na formação inicial de professores de português. Trabalhos em Linguística Aplicada, 47(1): 183-201. http://dx.doi.org/10.1590/S0103-18132008000100011

Kellner A. (2015) Apresentação: para onde caminha a paleontologia brasileira? Ciência e Cultura, 67(4): 20-24. http://dx.doi.org/10.21800/2317-66602015000400009

Kortz K.M. \& Murray D.P. (2009) Barriers to College Students Learning How Rocks Form. Journal of Geoscience Education, 57(4): 300-315. https://doi.org/10.5408/1.3544282 
Libâneo J.C. (1993) Organização e gestão escolar: teoria e prática. Goiânia: Alternativa. 270 p.

Lima R.M., Silva M.S.L., Almeida J.M., Véras M.A.S. \& Cavalcanti M.L.F. (2015) Contribuições da disciplina de paleontologia e evolução para a formação dos licenciados em ciências biológicas do CCA-UFPB (p. 22259-22268). In: Anais do XII Congresso Nacional de Educação. Volume 12. Curitiba: CONEDU.

Martindale R.C. \& Weiss A.M. (2020) "Taphonomy: Dead and Fossilized": A new board game designed to teach college undergraduate students about the process of fossilization. The Journal of Geoscience Education, 68(3): 265-285. https://doi.org/10.1080/10899995.2019.1693217

Mendonça A.P. (2015) Alinhamento Construtivo: Fundamentos e Aplicações (p. 109-130). In: Gonzaga A.M. (Ed.). Formação de Professores no Ensino Tecnológico: Fundamentos e Desafios. Curitiba: CRV. 300 p.

Oliva E. (2018) Ensino da Paleontologia em espaços não formais. Dissertação (Programa de PósGraduação em Paleontologia). Faculdade de Ciências e Tecnologia, Universidade de Évora/ Universidade Nova de Lisboa, Évora, Portugal.

Schweitzer M.H. (2003) Reviews and Previews: The Future of Molecular Biology. Palaeontologia Electronica, 5(2): 1-11.

Schweitzer M.H. (2004) Molecular paleontology: some current advances and problems. Annales de Paléontologie, 90(2): 81-102. https://doi.org/10.1016/j.annpal.2004.02.001

Schweitzer M.H. (2011) Soft Tissue Preservation in Terrestrial Mesozoic Vertebrates. Annual Review of Earth and Planetary Sciences, 39: 187-216. https://doi.org/10.1146/annurev-earth040610-133502

Schweitzer M.H., Schroeter E.R. \& Czajka C.D. (2020) Dinosaurs: How We Know What We Know. Boca Raton: CRC Press. 562 p.

Silva D.C., Reis R.A., Silva L.E. \& Domiciano T.D. (2019) Paleontologia e ensino de ciências: uma análise dos documentos oficiais e materiais presentes nos anos finais do ensino fundamental. ACTIO: Docência em Ciências, 4(1): 111-126. https://doi.org/10.3895/actio.v4n1.8001

Sousa R.C., Silva I.R., Santos S.F., Figueiredo A.E.Q. \& Fortier D.C. (2016) O ensino de Paleontologia nas escolas públicas estaduais de Floriano-PI na concepção dos docentes. In: III Congresso Nacional de Educação no Estado do Rio Grande do Norte. Natal, Rio Grande do Norte.

Teixeira P.P. (2016) Ensino de evolução e religiosidade: o caso de duas escolas estaduais do Rio de Janeiro. Tese (Programa de Pós-Graduação em Educação). Pontifícia Universidade Católica do Rio de Janeiro, Rio de Janeiro.

Thomas B. \& Taylor S. (2019) Proteomes of the past: the pursuit of proteins in Paleontology. EXpert Review of Proteomics, 16(11-12): 881-895. https://doi.org/10.1080/14789450.2019.1700114

Unicesumar (2017a) PPC - Projeto Pedagógico do Curso de Bacharelado em Ciências Biológicas. Ponta Grossa: Faculdade Cesumar de Ponta Grossa - IES 17420. 171 p.

Unicesumar (2017b) PPC - Projeto Pedagógico do Curso de Licenciatura em Ciências Biológicas. Ponta Grossa: Faculdade Cesumar de Londrina - IES 17632.159 p.

van der Reest A.J. \& Currie P.J. (2020) Preservation frequency of tissue-like structures in vertebrate remains from the upper Campanian of Alberta: Dinosaur Park Formation. Cretaceous Research, 109: 104370. https://doi.org/10.1016/j.cretres.2019.104370

Whitear M. (1956) XCVII.-On the colour of an ichthyosaur. Annals and Magazine of Natural History, 9(106): 742-744. https://doi.org/10.1080/00222935608655889

Worheide G., Dohrmann M. \& Yang Q. (2016) Molecular paleobiology - Progress and perspectives. Palaeoworld, 25(2): 138-148. https://doi.org/10.1016/j.palwor.2015.01.005

Zucon M.H., Vieira F.S., Prazeres M.F.F. \& Dantas M.A.T. (2010) O ensino de Paleontologia e a percepção dos alunos do curso de Biologia da Universidade Federal de Sergipe. In: Anais do IV Colóquio Intern. Educ. e Contemporaneidade. Aracaju: EdUFS. 
Anexo I - Plano de Aula

\begin{tabular}{|l|l|}
\hline \multicolumn{2}{|c|}{ Plano de Aula } \\
\hline Curso: Ciências biológicas - Licenciatura e Bacharelado & Setor: \\
\hline Departamento: & Código: \\
\hline Disciplina: Paleontologia & Ano / Semestre: \\
\hline Turma: & Período: \\
\hline Tema: Paleontologia Molecular & \\
\hline Professor responsável/Visitante: & Carga horária total: 2H \\
\hline Carga horária semanal: $2 \mathrm{H}$ & \\
\hline
\end{tabular}

\section{EMENTA:}

Breve história do campo de pesquisa, conceitos e terminologias básicas da área. Classes de biomoléculas de diferentes idades geológicas quanto ao seu potencial de preservação. Biomarcadores e métodos de recuperação de biomoléculas de fósseis. Tipos de informações que as biomoléculas produzem sobre a biologia, fisiologia e relações filogenéticas de organismos extintos. Noção geral de recursos básicos de um laboratório paleomolecular. Os diferentes grupos de técnicas analíticas empregados para recuperar e interpretar biomoléculas originais em fósseis e critérios para determinar sua endogeneidade. Mecanismos diagenéticos de preservação, modificações moleculares ao longo do tempo e aspectos da geoquímica no que se refere à retenção/preservação molecular. Perspectivas futuras e as implicações da Paleontologia molecular para outras disciplinas.

\section{OBJETIVOS}

\section{Objetivo geral:}

- Ensinar a importância das pesquisas paleomoleculares para a compreensão da evolução de organismos extintos.

\section{Objetivos específicos:}

- Avaliar criticamente a literatura pertinente e desenvolver habilidades de leitura crítica;

- Discutir os processos de diagênese e tafonomia em nível molecular, incluindo vários modos de preservação e modificações químicas em moléculas preservadas no registro fóssil;

- Discorrer sobre os principais grupos de técnicas de última geração para identificação de biomoléculas endógenas em fósseis;

- Levar o aluno a compreensão do potencial de preservação molecular e à adquirir habilidade de diferenciar a preservação de várias classes de biomoléculas.

\begin{tabular}{|c|l|l|}
\hline \multicolumn{2}{|c|}{ CONTEÚDO PROGRAMÁTICO } \\
\hline Data/ Horário & \multicolumn{1}{|c|}{ Tópicos } & \multicolumn{1}{|c|}{ Leituras } \\
\hline Dia 1-08:00 - 08:50 & $\begin{array}{l}\text { Abelson (1956); Whitear (1956); Isaacs } \\
\text { Breve histórico da Paleontologia } \\
\text { Molecular }\end{array}$ & $\begin{array}{l}\text { et al. (1963); Pawlicki et al. (1966); } \\
\text { Higuchi et al. (1984); Schweitzer et al. } \\
\text { (2005); Worheide et al. (2016); Alves } \\
\text { (2020). }\end{array}$ \\
\hline Dia 1-08:00 - 08:50 & $\begin{array}{l}\text { Definições, Ramos da Paleontologia } \\
\text { Molecular e Campos de pesquisa }\end{array}$ & $\begin{array}{l}\text { Schweitzer (2003); Schweitzer (2004); } \\
\text { Bailleul et al. (2019). }\end{array}$ \\
\hline Dia 1-08:00 - 08:50 & $\begin{array}{l}\text { Objeto de estudo, Biomarcadores e } \\
\text { Classes de biomoléculas originais } \\
\text { encontradas em fósseis }\end{array}$ & $\begin{array}{l}\text { Briggs et al. (2000); Gupta (2014); } \\
\text { Alves \& Machado (2020). }\end{array}$ \\
\hline
\end{tabular}




\begin{tabular}{|c|c|c|}
\hline Dia 1 - 08:00 - 08:50 & $\begin{array}{l}\text { Diagênese das rochas, Tafonomia, } \\
\text { Preservação excepcional e tipos de } \\
\text { tecidos moles em relação à diagênese } \\
\text { das rochas de depósitos sedimentares } \\
\text { Konservat-Lagerstätten }\end{array}$ & $\begin{array}{l}\text { Gobbo \& Bertini (2015); Parry et al. } \\
\text { (2018); Alves \& Machado (2020). }\end{array}$ \\
\hline Dia 1 - 08:00 - 08:50 & $\begin{array}{l}\text { Principais achados de biomoléculas } \\
\text { distribuídos ao longo da Coluna } \\
\text { geológica }\end{array}$ & $\begin{array}{l}\text { Towe \& Urbanek (1972); Kolesnikov } \\
\text { \& Egorov (1977); Schweitzer (2011); } \\
\text { Cody et al. (2011); Ehrlich et al. } \\
\text { (2013); Moczydlowska et al. (2014); } \\
\text { Alleon et al. (2016); Bobrovskiy et al. } \\
\text { (2018); Thomas \& Taylor (2019); } \\
\text { Alves \& Machado (2020); Gomes et al. } \\
\text { (2020a,b). }\end{array}$ \\
\hline Dia 1 - 08:00 - 08:50 & $\begin{array}{l}\text { Introdução ao laboratório de } \\
\text { Paleontologia Molecular e Métodos } \\
\text { analíticos de detecção de biomoléculas }\end{array}$ & $\begin{array}{l}\text { Schweitzer et al. (2005); DeSalle \& } \\
\text { Egan (2006); Schweitzer et al. (2013, } \\
\text { 2020); Gupta (2014); Taylor (2019); } \\
\text { Gomes (2020a,b). }\end{array}$ \\
\hline Dia $2-08: 00-08: 50$ & $\begin{array}{l}\text { Proteínas e DNA antigos e métodos de } \\
\text { detecção }\end{array}$ & $\begin{array}{l}\text { Marota \& Rollo (2002); DeSalle \& } \\
\text { Egan (2006); Schweitzer et al. (2009); } \\
\text { Lindgren et al. (2011); Gupta (2014); } \\
\text { Schroeter et al. (2017). }\end{array}$ \\
\hline Dia 2 - 08:00 - 08:50 & $\begin{array}{l}\text { Aplicações práticas da Paleontologia } \\
\text { Molecular: estudo de casos brasileiros }\end{array}$ & $\begin{array}{l}\text { Pinheiro et al. (2019); Campos \& } \\
\text { Kischlat (2020). }\end{array}$ \\
\hline Dia $2-08: 00$ - 08:50 & $\begin{array}{l}\text { A importância da Pesquisa teórica } \\
\text { brasileira relativa à Frequência de } \\
\text { Ocorrência de achados de biomateriais } \\
\text { não mineralizados no mundo }\end{array}$ & $\begin{array}{l}\text { Thomas \& Taylor (2019); Alves \& } \\
\text { Machado (2020); Gomes et al. } \\
\text { (2020a,b). }\end{array}$ \\
\hline Dia $2-08: 00-08: 50$ & $\begin{array}{l}\text { Sobrevivência esperada de biomoléculas } \\
\text { a diferentes temperaturas }\end{array}$ & $\begin{array}{l}\text { Gilbert et al. (2007); Buckley \& } \\
\text { Collins (2011); Allentoft et al. (2012); } \\
\text { Dabney et al. (2013); Wadsworth \& } \\
\text { Buckley (2014); Schweitzer et al. } \\
\text { (2014); Alves \& Machado (2020); Pan } \\
\text { (2020); Bailleul et al. (2020). }\end{array}$ \\
\hline Dia 2 - 08:00 - 08:50 & $\begin{array}{l}\text { Principais mecanismos diagenéticos de } \\
\text { preservação de biomoléculas originais e } \\
\text { as mais relevantes controvérsias } \\
\text { relacionadas }\end{array}$ & $\begin{array}{l}\text { Schweitzer et al. (2014); Gobbo \& } \\
\text { Bertini (2015); Parry et al. (2018); } \\
\text { Thomas \& Taylor (2019); Armitage \& } \\
\text { Solliday (2020); Wiemann et al. } \\
\text { (2020); Alves \& Machado (2020). }\end{array}$ \\
\hline Dia $2-08: 00$ - 08:50 & $\begin{array}{l}\text { Perspectivas futuras da Paleontologia } \\
\text { Molecular, Discussão e Avaliação }\end{array}$ & $\begin{array}{l}\text { DeSalle \& Egan (2006); Thomas \& } \\
\text { Taylor (2019); Alves \& Machado } \\
\text { (2020); Pan (2020). }\end{array}$ \\
\hline
\end{tabular}

\section{RECURSOS DIDÁTICOS:}

- computador

- projetor multimídia

- quadro negro e giz (ou quadro branco e pincel)

\begin{tabular}{|l|c|}
\hline \multicolumn{2}{|c|}{ PROCEDIMENTOS DE AVALIAÇÃO } \\
\hline Método de avaliação & $\%$ de 100 pts total \\
\hline Participação em sala de aula e leitura antes da discussão em classe. & 20 pts $(20 \%)$ \\
\hline Avaliação - questionário & 80 pts $(80 \%)$ \\
\hline
\end{tabular}




\section{BIBLIOGRAFIA}

Bibliografia básica:

- Alves E.F. (2020) 15 anos da Paleontologia molecular: breve histórico dos achados de tecidos moles não mineralizados em dinossauros não avianos. Khronos, Revista de História da Ciência, 9: 241-244. https://doi.org/10.11606/khronos.v0i9.172317

- Alves E.F. \& Machado M.F. (2020) Perspectivas atuais sobre tecidos moles não mineralizados em fósseis de dinossauros não avianos. Terræ Didatica, 16: 1-14, e020028. https://doi.org/10.20396/td.v16i0.8659539

- DeSalle R. \& Egan M.G. (2006) Paleontology, Molecular (p. 53-70). In: Reviews in Cell Biology and Molecular Medicine. Weinheim, Germany: Wiley-VCH Verlag GmbH \& Co. KGaA.

- Gobbo S.R. \& Bertini R. (2015) Tecidos moles (não resistentes): como se fossilizam? Terræ Didatica, 10(1): 2-13. https://doi.org/10.20396/td.v10i1.8637374

- Gomes W.A., Machado M.F., Bélo P. \& Alves E.F. (2020a) Biomoléculas em fósseis de mamíferos cenozoicos: reivindicações de tecidos moles não mineralizados em fósseis recuperados de diferentes contextos tafonômicos. In: Paleo RJ/ES Virtual, Vitória-ES.

- Gomes W.A., Machado M.F., Bélo P. \& Alves E.F. (2020b) Paleontologia molecular do Cenozoico: reivindicações de tecidos moles não mineralizados em mamíferos encontrados em depósitos sedimentares pouco favoráveis à preservação. In: Paleo RJ/ES Virtual, Vitória-ES.

- Gupta N.S. (2014) Biopolymers: A molecular paleontology approach (Topics in Geobiology Book 38). Dordrecht: Springer, Kindle Edition. 199 p.

- Schweitzer M.H., Schroeter E.R. \& Czajka C.D. (2020). Dinosaurs: How We Know What We Know. Boca Raton: CRC Press, 2020. 562 p.

\section{Bibliografia complementar}

- Abelson P.H. (1956). Paleobiochemistry. Scientific American, 195(1): 83-92.

- Allentoft M.E., Collins M., Harker D., Haile J., Oskam C.L., Hale M.L., Campos P.F., Samaniego J.A., Gilbert M.T.P., Willerslev E., Zhang G., Paul Scofield R., Holdaway R.N. \& Bunce M. (2012) The halflife of DNA in bone: measuring decay kinetics in 158 dated fossils. Proceedings of the Royal Society B: Biological Sciences, 279(1748): 4724-4733. https://doi.org/10.1098/rspb.2012.1745

- Alleon J., Bernard S., Le Guillou C., Marin-Carbonne J., Pont S., Beyssac O., McKeegan K.D. \& Robert F. (2016) Molecular preservation of $1.88 \mathrm{Ga}$ Gunflint organic microfossils as a function of temperature and mineralogy. Nature Communications, 7: 11977.

https://doi.org/10.1038/ncomms11977

- Armitage M.H. \& Anderson K.L. (2013) Soft sheets of fibrillar bone from a fossil of the supraorbital horn of the dinosaur Triceratops horridus. Acta Histochemica, 115(6): 603-608.

https://doi.org/10.1016/j.acthis.2013.01.001

- Armitage M.H. \& Anderson K.L. (2014) Light and Electron Microscopic Study of Soft Bone Osteocytes From a Triceratops horridus Supraorbital Horn. Microscopy and Microanalysis, 20(Suppl. S3): 1274-1275.

- Armitage M.H. \& Solliday J. (2020) UV Autofluorescence Microscopy of Dinosaur Bone Reveals Encapsulation of Blood Clots within Vessel Canals. Microscopy Today, 28(5): 30-38. https://doi.org/10.1017/S1551929520001340

- Bailleul A.M., O’Connor J. \& Schweitzer M.H. (2019) Dinosaur paleohistology: review, trends and new avenues of investigation. PeerJ, 7: e7764. https://doi.org/10.7717/peerj.7764

- Bailleul A.M., Zheng W., Horner J.R., Hall B.K., Holliday C.M. \& Schweitzer M.H. (2020) Evidence of proteins, chromosomes and chemical markers of DNA in exceptionally preserved dinosaur cartilage. National Science Review, 7(4): 815-822. https://doi.org/10.1093/nsr/nwz206

- Bobrovskiy I., Hope J.M., Ivantsov A., Nettersheim B.J., Hallmann C. \& Brocks J.J. (2018) Ancient steroids establish the Ediacaran fossil Dickinsonia as one of the earliest animals. Science, 361(6408): 1246-1249. https://doi.org/10.1126/science.aat722

- Briggs D.E.G., Evershed R.P. \& Lockheart M.J. (2000) The Biomolecular Paleontology of Continental Fossils. Paleobiology, 26(4): 169-193. 
- Buckley M. \& Collins M.J. (2011) Collagen survival and its use for species identification in Holocene-Lower Pleistocene bone fragments from British archaeological and paleontological sites. Antiqua, 1(1): e1. https://doi.org/10.4081/antiqua.2011.e1

- Campos H.B.N. \& Kischlat E.E. (2020) The tapejarid pterosaur Tupandactylus imperator from Crato Formation and the preservation of cranial integuments. bioRxiv. https://doi.org/10.1101/2020.02.06.937458

- Cody G.D., Gupta N.S., Briggs D.E.R., Kilcoyne A.L.D., Summons R.E., Kenig F., Plotnick R.E. \& Scott A.C. (2011) Molecular signature of chitin-protein complex in Paleozoic arthropods. Geology, 39(3): 255-258. https://doi.org/10.1130/G31648.1

- Dabney J., Meyer M. \& Pääbo S. (2013) Ancient DNA damage. Cold Spring Harbor Perspectives in Biology, 5(7): a012567. https://doi.org/10.1101/cshperspect.a012567

- Ehrlich H., Rigby J.K., Botting J.P., Tsurkan M.V., Werner C., Schwille P., Petrášek Z., Pisera A., Simon P., Sivkov V.N., Vyalikh D.V., Molodtsov S.L., Kurek D., Kammer M., Hunoldt S., Born R., Stawski D., Steinhof A., Bazhenov V.V. \& Geisler T. (2013) Discovery of 505-million-year old chitin in the basal demosponge Vauxia gracilenta. Scientific Reports, 3: 3497. https://doi.org/10.1038/srep03497

- Gilbert M.T., Tomsho L.P., Rendulic S., Packard M., Drautz D.I., Sher A., Tikhonov A., Dalén L., Kuznetsova T., Kosintsev P., Campos P.F., Higham T., Collins M.J., Wilson A.S., Shidlovskiy F., Buigues B., Ericson P.G., Germonpré M., Götherström A., Iacumin P., Nikolaev V., Nowak-Kemp M., Willerslev E., Knight J.R., Irzyk G.P., Perbost C.S., Fredrikson K.M., Harkins T.T., Sheridan S., Miller W. \& Schuster S.C. (2007) Whole-genome shotgun sequencing of mitochondria from ancient hair shafts. Science, 317(5846): 1927-1930.

- Higuchi R., Bowman B., Freiberger M., Ryder O.A. \& Wilson A.C. (1984) DNA sequences from the quagga, an extinct member of the horse family. Nature, 312(5991): 282-284. https://doi.org/10.1038/312282a0

- Isaacs W.A., Little K., Currey J.D. \& Tarlo L.B. (1963) Collagen and a cellulose-like substance in fossil dentine and bone. Nature, 197: 192. https://doi.org/10.1038/197192a0

- Kolesnikov M.P. \& Egorov I.A. (1977) Porphyrins and phycobilins in Precambrian rocks. Origins Life Evol Biosphere, 8: 383-390. https://doi.org/10.1007/BF00927910

- Lindgren J., Uvdal P., Engdahl A., Lee A.H., Alwmark C., Bergquist K.E., Nilsson E., Ekström P., Rasmussen M., Douglas D.A., Polcyn M.J. \& Jacobs L.L. (2011) Microspectroscopic evidence of cretaceous bone proteins. PLoS One, 6(4): e19445. https://doi.org/10.1371/journal.pone.0019445

- Marota I. \& Rollo F. (2002) Molecular paleontology. CMLS Cellular and Molecular Life Sciences, 59: 97-111.

- Moczydlowska M., Westall F. \& Foucher F. (2014) Microstructure and Biogeochemistry of the Organically Preserved Ediacaran Metazoan Sabellidites. Journal of Paleontology, 88(2): 224-239. https://doi.org/10.1666/13-003

- Pan Y. (2020) Molecular paleontology as an exciting, challenging and controversial field. National Science Review, 7(4): 823. https://doi.org/10.1093/nsr/nwaa001

- Parry L.A., Smithwick F., Nordén K.K., Saitta E.T., Lozano-Fernandez J., Tanner A.R., Caron J.B., Edgecombe G.D., Briggs D.E.G. \& Vinther J. (2018) Soft-Bodied Fossils Are Not Simply Rotten Carcasses - Toward a Holistic Understanding of Exceptional Fossil Preservation: Exceptional Fossil Preservation Is Complex and Involves the Interplay of Numerous Biological and Geological Processes. Bioessays, 40(1): 1700167. https://doi.org/10.1002/bies.201700167

- Pawlicki R. (1995) Histochemical demonstration of DNA in osteocytes from dinosaur bones. Folia Histochemica et Cytobiologica, 33(3): 183-186.

- Pawlicki R., Dkorbel A. \& Kubiak H. (1966) Cells, collagen fibrils and vessels in dinosaur bone. Nature, 211(5049): 655-657.

- Pinheiro F.L., Prado G., Ito S., Simon J.D., Wakamatsu K., Anelli L.E., Andrade J.A.F. \& Glass K. (2019) Chemical characterization of pterosaur melanin challenges color inferences in extinct animals. Scientific Reports, 9: 15947. https://doi.org/10.1038/s41598-019-52318-y

- Schroeter E.R., DeHart C.J., Cleland T.P., Zheng W., Thomas P.M., Kelleher N.L., Bern M. \& Schweitzer M.H. (2017) Expansion for the Brachylophosaurus canadensis collagen I sequence and additional evidence of the preservation of cretaceous protein. Journal of Proteome Research, 16(2): 920-932. https://doi.org/10.1021/acs.jproteome.6b00873 
- Schweitzer M.H. (2003) Reviews and Previews: The Future of Molecular Biology. Palaeontologia Electronica, 5(2): 1-11.

- Schweitzer M.H. (2004) Molecular paleontology: some current advances and problems. Annales de Paléontologie, 90(2): 81-102. https://doi.org/10.1016/j.annpal.2004.02.001

- Schweitzer M.H. (2011) Soft Tissue Preservation in Terrestrial Mesozoic Vertebrates. Annual Review of Earth and Planetary Sciences, 39: 187-216. https://doi.org/10.1146/annurev-earth-040610-133502

- Schweitzer M.H., Wittmeyer J.L., Horner J.R. \& Toporski J.K. (2005) Soft-tissue vessels and cellular preservation in Tyrannosaurus rex. Science, 307(5717): 1952-1955. https://doi.org/10.1126/science.1108397

- Schweitzer M.H., Zheng W., Cleland T.P. \& Bern M. (2013) Molecular analyses of dinosaur osteocytes support the presence of endogenous molecules. Bone, 52(1): 414-23. https://doi.org/10.1016/j.bone.2012.10.010

- Schweitzer M.H., Johnson C., Zocco T.G., Horner J.R. \& Starkey J.R. (1997) Preservation of biomolecules in cancellous bone of Tyrannosaurus rex. Journal of Vertebrate Paleontology, 17(2): 349-359. https://doi.org/10.1080/02724634.1997.10010979

- Schweitzer M.H., Zheng W., Organ C.L., Avci R., Suo Z., Freimark L.M., Lebleu V.S., Duncan M.B., Vander Heiden M.G., Neveu J.M., Lane W.S., Cottrell J.S., Horner J.R., Cantley L.C., Kalluri R. \& Asara J.M. (2009) Biomolecular characterization and protein sequences of the Campanian hadrosaur B. canadensis. Science, 324(5927): 626-631. https://doi.org/10.1126/science.1165069

- Schweitzer M.H., Zheng W., Cleland T.P., Goodwin M.B., Boatman E., Theil E., Marcus M.A. \& Fakra S.C. (2014) A role for iron and oxygen chemistry in preserving soft tissues, cells and molecules from deep time. Proceedings of the Royal Society B: Biological Sciences, 281(1775): 20132741. https://doi.org/10.1098/rspb.2013.2741

- Thomas B. \& Taylor S. (2019) Proteomes of the past: the pursuit of proteins in Paleontology. Expert Review of Proteomics, 16(11-12): 881-895. https://doi.org/10.1080/14789450.2019.1700114

- Towe K.M. \& Urbanek A. (1972) Collagen-like Structures in Ordovician Graptolite Periderm. Nature, 237: 443. https://doi.org/10.1038/237443a0

- Wadsworth C. \& Buckley M. (2014) Proteome degradation in fossils: investigating the longevity of protein survival in ancient bone. Rapid Communications in Mass Spectrometry, 28(6): 605-615. https://doi.org/10.1002/rcm.6821

- Whitear M. (1956). XCVII.-On the colour of an ichthyosaur. Annals and Magazine of Natural History: Series 12, 9(106): 742-744.

- Wiemann J., Crawford J.M. \& Briggs D.E.G. (2020) Phylogenetic and physiological signals in metazoan fossil biomolecules. Science Advances, 6(28): eaba6883. https://doi.org/10.1126/sciadv.aba6883

- Worheide G., Dohrmann M. \& Yang Q. (2016) Molecular paleobiology - progress and perspectives. Palaeoworld, 25(2): 138-148. https://doi.org/10.1016/j.palwor.2015.01.005 
Anexo II - Questionário

1. Defina "Paleontologia Molecular".

2. A Paleontologia Molecular há décadas vem sendo abordada pela indústria cinematográfica que, inclusive, ampliou a sua divulgação científica e estimulou gerações de jovens a se envolverem com pesquisas paleomoleculares. Diante disso, qual o nome do filme hollywoodiano lançado em 1993 que ajudou a desenvolver a tecnologia por trás da investigação fóssil em busca de DNA antigo?

(A) Em busca dos fósseis

(B) Indiana Jones

(C) Jurassic Park

(D) Dinossauro (Walt Disney)

3. Quais os principais ramos da Paleontologia Molecular?

(A) Paleontologia e Biologia Molecular

(B) Paleomedicina e Paleogenética

(C) Paleoquímica e Paleogeologia

(D) Paleogenômica e Paleoproteômica

4. Qual é o objeto de estudo da Paleontologia Molecular?

(A) Compostos químicos elementares (Ca, P, Zn, etc...)

(B) Tecidos duros

(C) Biomateriais não mineralizados

(D) Apenas fósseis permineralizados

5. Embora a Paleontologia Molecular tenha se popularizado somente em 2005, sabe-se que os achados de biomoléculas originais são bem mais antigos (descritos nas décadas de 1950 e 1960). Quais foram os primeiros organismos fósseis nos quais foram encontrados restos de biomateriais originais?

(A) Mamute e Smilodon

(B) Mastodonte e Eremotherium

(C) Pterossauro e Plesiosaurus

(D) Conchas e dinossauros

6. Mary Schweitzer, paleontóloga norte-americana, hoje é considerada a Patronese da Paleontologia Molecular devido a seus esforços e descobertas terem popularizado mundialmente os achados de biomateriais não mineralizados em fósseis, principalmente a partir da publicação polêmica em 2005 na revista Science. Qual foi essa descoberta?

(A) Células e vasos sanguíneos flexíveis e ocos em um T. rex de 68 milhões de anos

(B) Proteínas e DNA em um mamute da Idade do gelo (13 mil anos atrás)

(C) Tecidos mumificados de uma preguiça gigante de 23 mil anos

(D) DNA excepcional em um mosquito preservado em âmbar de 350 milhões de anos

7. Segundo o paradigma da Paleobiologia, quais são as médias de tempo máximas de sobrevivência esperada para biomoléculas lábeis como DNA e proteína, sucessivamente, em ambientes naturais?

(A) Entre 100 milhões de anos e 200 milhões de anos

(B) Por tempo indeterminado

(C) 100 mil e 1 milhão de anos

(D) 100 anos e 10 mil anos

8. Biomateriais não mineralizados são compostos por quais tipos de estruturas?

(A) Proteínas e DNA, apenas.

(B) Tecidos moles, células, moléculas orgânicas e/ou seus produtos de degradação

(C) Tecido cartilaginoso, tecido ósseo, tendões e tecido musculoesquelético 
(D) Todas as respostas anteriores

9. Quais são os principais tipos de tecidos moles em relação à diagênese dos fósseis?

(a) Tecido mole intacto, tecido mole endógeno e tecido mole fossilizado

(b) Tecido mole fossilizado, tecido mole mumificado e tecido mole calcificado

(c) Tecido mole petrificado, tecido mole desnaturado e tecido mole mineralizado

(d) Tecido mole mineralizado ou parcialmente mineralizado e tecido mole não mineralizado

10. Quais os principais fatores de degradação das biomoléculas originais em ambientes naturais? Assinale a alternativa correta.

(A) Microorganismos decompositores, temperatura baixa, chuva, oxigênio

(B) Radiação solar, água percolante, variação de temperatura, microorganismos decompositores

(C) Ambientes áridos, microorganismos decompositores, $\mathrm{pH}$ básico, chuva, oxigênio

(D) Raízes de plantas, microorganismos decompositores, frio, oxigênio, chuva

11. Sabe-se que ácidos nucléicos se degradam facilmente em ambientes não controlados (isto é, fora de laboratórios). Porém, já foram encontrados vestígios de DNA antigo em fósseis de dinossauros. Qual é o estado de preservação em que se encontram essas moléculas de DNA?

(A) Ótimo estado de preservação, em grande quantidade, podendo ser seqüenciado e replicado.

(B) Bom estado de preservação, em pouca quantidade, podendo ser apenas seqüenciado.

(C) Reconhecível principalmente por métodos imunohistoquímicos, pequena quantidade, não podendo ser seqüenciado e replicado.

(D) Péssimo estado de preservação, mineralizado, e em pouca quantidade.

12. Em qual grupo taxonômico de seres vivos é possível encontrar biomateriais não mineralizados?

(A) Plantas e procariotos

(B) Animais invertebrados

(C) Animais vertebrados

(D) Todas as alternativas anteriores

13. A preservação excepcional de biomateriais não mineralizados em tempo profundo tem sido associada a alguns dispositivos de preservação que ocorrem naturalmente durante a diagênese (formação) das rochas. Em qual etapa da formação da rocha é fundamental que esses dispositivos "encapsulem" as biomoléculas orgânicas a fim de impedir contato com microorganismos decompositores e fatores abióticos de degradação?
(A) Telodiagênese
(B) Mesodiagênese
(C) Rochadiagênese
(D) Eodiagênese

14. Embora os mecanismos de preservação de biomoléculas originais em tempo profundo ainda hoje sejam parcialmente incompreendidos, algumas explicações têm sido propostas na literatura científica a fim de cobrir essa lacuna. Assinale a alternativa que contenha os principais mecanismos mais comumente aceitos.

(A) Adesão biomineral, preservação por Ferro, modelo da "tostada"

(B) Encapsulamento, ligações químicas mediadas por bactérias, formaldeído

(C) Radicais livres de oxigênio, folmaldeído, anoxia

(D) Ferro redox-ativo, soterramento rápido, desoxia

15. A Paleontologia tem "emprestado" técnicas para análises de fósseis de muitas outras áreas do conhecimento, tais como da Medicina, Biologia Molecular, Bioquímica, Biofísica, Geologia, Bioinformática, entre outras. Porém, em relação à Paleontologia Molecular, especificamente, podemos agrupar em três categorias distintas os métodos utilizados para identificação de biomoléculas orgânicas. São eles:
(A) Óptico, químico e biológico
(B) Físico, químico e biológico
(C) Biológico, cristalografia, espectroscopia
(D) Imunológico, biológico e químico 